\title{
Application of Forecasting Techniques in Nissan Urvan Income Generation of Anambra State Transport Sector
}

\author{
${ }^{1}$ Godwin, Harold C., ${ }^{2}$ Umeozokwere, Anthony O., ${ }^{3}$ Ezemuo Daniel T. \\ ${ }^{1}$ Department of Industrial/Production Engineering, Nnamdi Azikiwe University, Awka \\ ${ }^{2,3}$ Department of Mechanical Engineering Technology, Federal Polytechnic Oko
}

\begin{abstract}
This research work studies several forecasting techniques to predict future income generation and its implications on the Nissan Urvan income generation in Anambra State Transport sector.This paper presents three forecasting models (time series decomposition method, winter's method and Arima method) to analyze data income generation of Anambra State Transport Sector over the period of 2005-2019, it is important to know the trend in Anambra Transport Sector to elicit patterns of incomes generated. However, the models used were based on applicable methodology to facilitate accurate and faster analysis of data. The results reveal that the future income generated for the products will continuously decrease with time. Having observed the values obtained from the models used, it is recommended that the company should employ time series decomposition forecasting model because it gives more accurate result with less error.
\end{abstract}

Keywords: Trend, Vehicle, Maintenance, Replacement, Income, Forecasting.

\section{INTRODUCTION}

Vehicles and equipment are subject to deterioration due to their use and exposure to environmental conditions as a result of wear and tear of parts in relative motion and improper lubrication of the sliding parts and should be fully utilized with minimum cost of stoppage and repair (Dieter, 2003).In reality, vehicles' breakdown due to unplanned maintenance (sudden failure) will increase the repair cost and machine downtime (Nakajima, 2009). If this deterioration and breakdown is not checked it may render the vehicles unserviceable, therefore, it is necessary to attend to them from time to time, repair and recondition them so as to enhance their life economically and protect them from failure (Godwin et al 2013). This has brought the role of maintenance and replacement as an important activity in the transportation industries.

Transportation is the hub of the economy, it connects people and makes people and places accessible and enhances social, economic and cultural interactions. Along with power and communication, transport is one of the social overhead capitals which must be developed to a critical minimum level in order to facilitate investments in other sectors (Steven, 2007). Transport remains the cornerstone of civilization. As the society and economic organizations become complex, the relevance of transport grows. Besides, the demand for transport is derived, because it depends on the demand for commodities carried or the benefit of personal travel and each travel is unique in time and space (Fischer, 2010). Hence, the demand for transport services increases with the extension of the inputoutput relationships of an economy. In Nigeria, transport's contribution to the Gross Domestic Product is relatively low. Vehicles should be fully utilized with minimum cost of stoppage and repair. Therefore; this has brought the role of income as an important activity in the transportation industries. Forecasting is the process of making statements about events whose actual outcomes (typically) have not yet been observed (Latham 2008). A commonplace example might be the estimation of some variables of interest at some specified future date. Prediction is a similar, but more general term. Usage can differ between areas of application: for example, in hydrology, meteorology etc. the terms "forecast" and "forecasting" are sometimes reserved for estimates of values at certain specific future times, while the term "prediction" is used for more general estimates, such as the number of times floods will occur over a long period (Shumway, 1988). However, Nissan Urvan of Anambra State Transport Sector was used as a case study. The work forecasts the income generation of the Nissan Urvan in the Anambra State Transport Sector in order to observe the number of years the vehicles can no longer be more useful to the company. To achieve this objective, three forecasting models (Time Series Decomposition Analysis Model, Winter Analysis Model and ARIMA Analysis Model) were used. 
Although, many forecasting approaches and models have been used in the past to forecast the income generation of transportation industries, but could not because such models were archaic, inaccurate, unrealistic and inconsistent which cannot estimate some variables of interest at some specified future date and could not be applied to a wide variety of situations (Dwaikat, 2009).With these proposed forecasting models, income generation of transportation industries can now be more accurate, consistent, realistic and will be modeled as a function of calendar data, meteorological data and economic variables can be established with certainty and product-based organizations can now forecast demand to minimize the cost of inventory while ensuring that their clients have access to their products. The objective of the study is the application of some selected forecasting techniques to forecast the income generated by Nissan Urvan of Anambra State Transport Sector.

\section{Methodology}

The research method used is the case study of the income generated by Nissan Urvan vehicles in Anambra State Transport Sector. The data on income generated by Nissan Urvan from 2005 to 2014 were used as actual data and was predicted up to 2019 using forecasting models for the planned period years. The data collected were analyzed using Trend Analysis Model, Winter Analysis Model and ARIMA Analysis Model.

\section{Method of Data Analysis}

\subsection{Time Series Decomposition Analysis Model}

$F_{t}=b t+a$

Where $\mathrm{t}=$ Specified number of time periods from $\mathrm{t}=\mathrm{o}$

$F_{t}=$ Forecast for period $\mathrm{t}$

$a=$ Value of $F_{t}$ at $\mathrm{t}=0$

$b=$ Slope of the line

$\mathrm{b}=\frac{n \sum t y-\sum t \sum y}{n \sum t^{2}-\left(\sum t\right)^{2}}$

$\mathrm{a}=\frac{\sum y-b \sum t}{n}$ or $\bar{y}-b \bar{t}$

Where, $\mathrm{n}=$ Number of periods

$\mathrm{y}=$ Value of the time series

\subsection{Winter Modeling}

$T_{t}=\beta\left(F_{t}-F_{t-1}\right)+(1-\beta) T_{t-1}$

$T_{t}=$ Trend estimate at time $\mathrm{t}$

$F_{t}=$ Exponential average at time $\mathrm{t}$

$\beta=$ fractions,

$f_{t}=\left(F_{t-1}-T_{t-1}\right)$

$F_{t}=\alpha D_{t}+(1-\alpha)\left(F_{t-1}-T_{t-1}\right)$

where $F_{t}=$ Forecast for period $\mathrm{t}$

$F_{t-1}=$ Forecast for the previous period

$\alpha=$ Smoothing constant (represents the percentage of the forecast error)

$D_{t}=$ Demand

$f_{t+1}=\left(F_{t}-T_{t}\right)$

$f_{t+1}=$ Winter Forecast 


\subsection{ARIMA (Auto-Regressive Integrated Moving Average)}

In terms of $y$, the general ARIMA forecasting model is:

$\hat{\mathrm{y}}_{\mathrm{t}}=\mu+\phi_{1} \mathrm{y}_{\mathrm{t}-1}+\ldots+\phi_{\mathrm{p}} \mathrm{y}_{\mathrm{t}-\mathrm{p}}-\theta_{1} \mathrm{e}_{\mathrm{t}-1}-\ldots-\theta_{\mathrm{q}} \mathrm{e}_{\mathrm{t}-\mathrm{q}}$

$\mu=$ constant

$\theta$ 's $=$ moving average parameters

$\mathrm{p} \geq 1=$ some number MA terms or AR terms

$\mathrm{e}=$ errors

$\vee_{t}=$ Forecast for period $\mathrm{t}$

$\phi=$ slope coefficient

\section{Data Presentation}

Table 1 shows the raw data collected from the case company (i.e.Anambra State Transport Sector).

Table1. Data of Nissan Urvan vehicle Income Generated(x100)

\begin{tabular}{|l|l|l|}
\hline S/N code & Years & Income Generated Data \\
\hline 1 & 2005 & 19,690 \\
\hline 2 & 2006 & 22,500 \\
\hline 3 & 2007 & 25,200 \\
\hline 4 & 2008 & 28,150 \\
\hline 5 & 2009 & 30,300 \\
\hline 6 & 2010 & 32,400 \\
\hline 7 & 2011 & 33,600 \\
\hline 8 & 2012 & 25,900 \\
\hline 9 & 2013 & 39,950 \\
\hline 10 & 2014 & 40,050 \\
\hline
\end{tabular}

Source: Anambra State Transport Sector

\section{ANAlysis AND ReSUlts}

Table 2 shows the analysis of the time series decomposition. Time series decomposition reveals the influence of the seasonality and trend in the data for over the period under investigation. The trend shows the future increase or decrease in the data under investigation, while the seasonal influence shows the effect of the seasonality in the data.

Table2. Time Series Decomposition for Nissan Urvan (Income Generated)

\begin{tabular}{|l|l|l|l|l|l|l|l|l|}
\hline Year & $\begin{array}{l}\text { Time } \\
\text { Code }\end{array}$ & $\begin{array}{l}\text { Nissan Urvan } \\
\text { (Income Generated) }\end{array}$ & Trend & Seasonal & Detrend & Deseason & Predict & Error \\
\hline 2005 & 1 & 98073 & 99149.5 & 0.99681 & 0.98914 & 98387.0 & 98833.0 & -760.03 \\
\hline 2006 & 2 & 97824 & 97186.6 & 1.00319 & 1.00656 & 97512.8 & 7496.8 & 327.19 \\
\hline 2007 & 3 & 96000 & 95223.8 & 0.99681 & 1.00815 & 96307.4 & 94919.9 & 1080.10 \\
\hline 2008 & 4 & 95150 & 93261.0 & 1.00319 & 1.02026 & 94847.3 & 93558.6 & 1591.38 \\
\hline 2009 & 5 & 90200 & 91298.1 & 0.99681 & 0.98797 & 90488.8 & 91006.8 & -806.76 \\
\hline 2010 & 6 & 88500 & 89335.3 & 1.00319 & 0.99065 & 88218.4 & 89620.4 & -1120.43 \\
\hline 2011 & 7 & 86100 & 87372.5 & 0.99681 & 0.98544 & 86375.7 & 87093.6 & -993.62 \\
\hline 2012 & 8 & 84897 & 85409.6 & 1.00319 & 0.99400 & 84626.9 & 85682.2 & -785.23 \\
\hline 2013 & 9 & 83400 & 83446.8 & 0.99681 & 0.99944 & 83667.0 & 83180.5 & 219.51 \\
\hline 2014 & 10 & 83000 & 81484.0 & 1.00319 & 1.01861 & 82735.9 & 81744.0 & 1255.96 \\
\hline
\end{tabular}

Table 3 shows the forecasting results of the data using time series decomposition analysis. The forecast shows future five years income generated in the aforementioned company using their Nissan Urvan product. 
Godwin, Harold C. et al.

Table3. Forecasting Results of Time Series Decomposition

\begin{tabular}{|l|l|}
\hline Period & Forecast \\
\hline 2015 & 79267.4 \\
\hline 2016 & 77805.8 \\
\hline 2017 & 75354.2 \\
\hline 2018 & 73867.7 \\
\hline 2019 & 71441.1 \\
\hline
\end{tabular}

Figure 1 reveals the results of time series decomposition analysis. It shows the trend of the data, fitness of the data, actual data plot, forecasting results of the data and the accuracy measures in the data. The graph also shows that as the year increases the income generation decreases and vice versa.

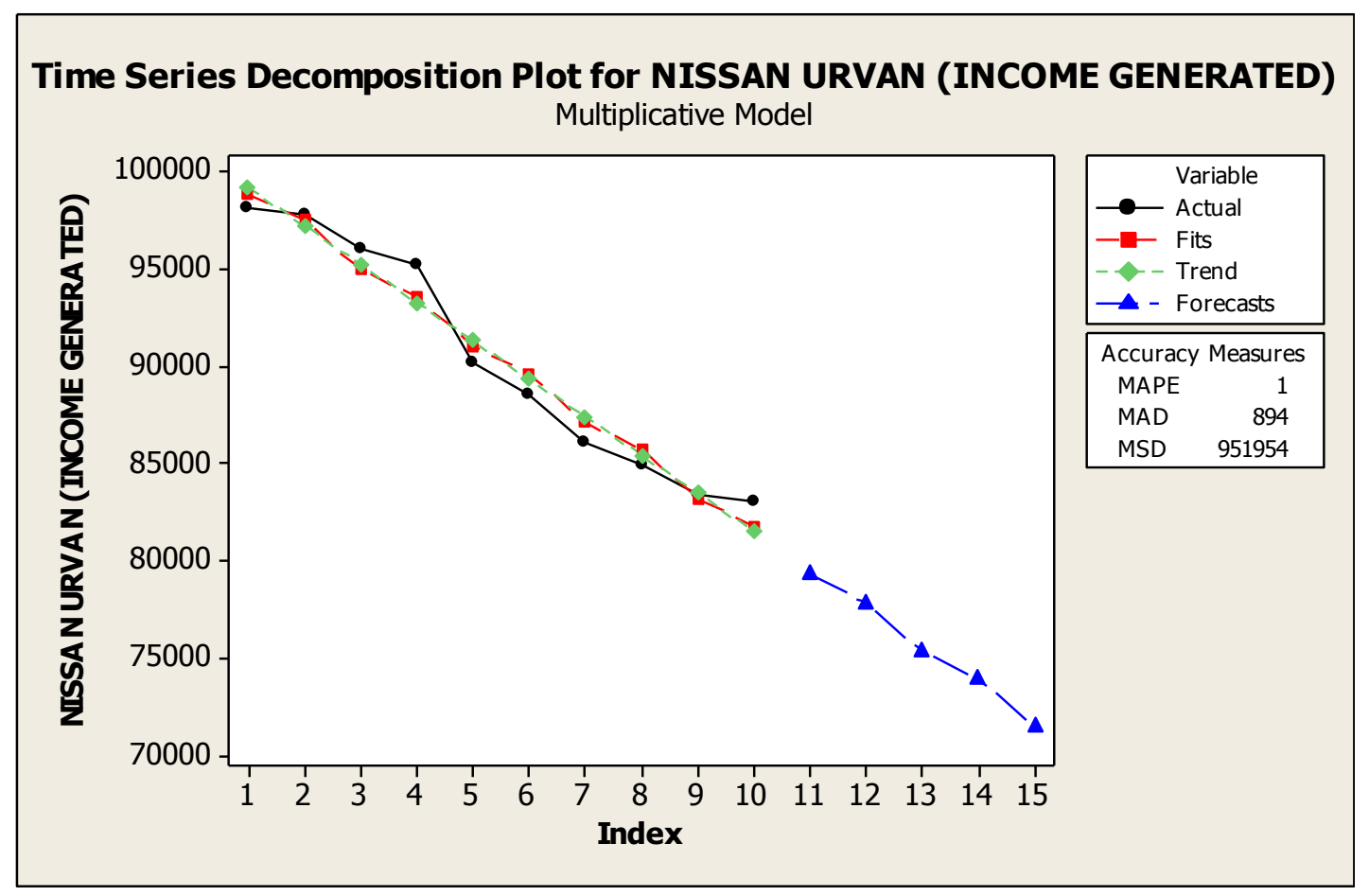

Figure1. Time Series Decomposition Plot for Nissan Urvan (Income Generated)

Figure 2 shows the component analysis of the data. It reveals the influence of adjusted seasoning and detrends of the data.

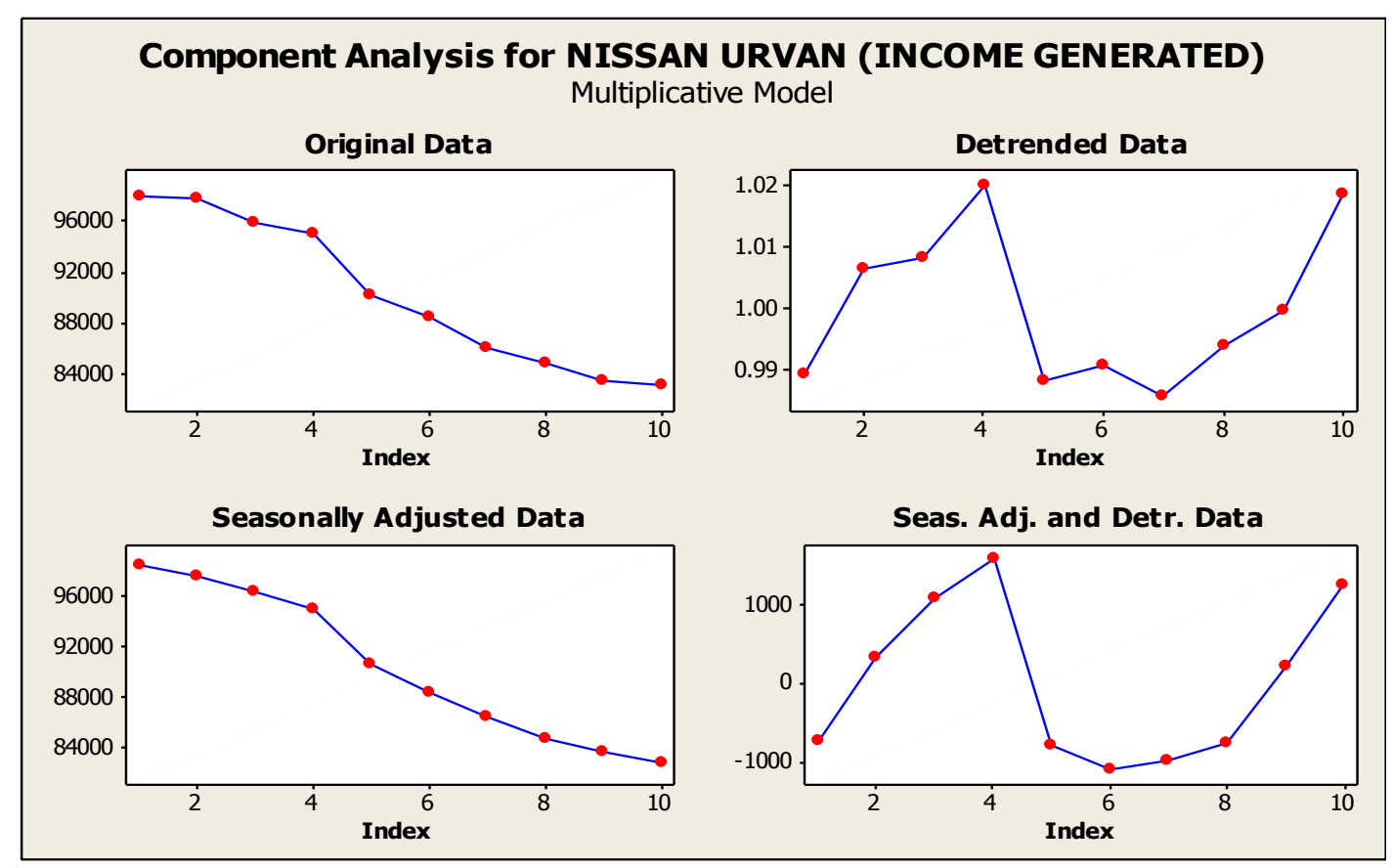

Figure2. Decomposition - Component Analysis for Nissan Urvan (Income Generated) 
Application of Forecasting Techniques in Nissan Urvan Income Generation of Anambra State Transport Sector

\section{WINTERS' METHOD FOR NISSAN URVAN (INCOME GENERATED)}

Table 4 reveals the analysis of winters' method of forecasting in the aforementioned case company using Nissan Urvan product. It reveals the smooth variables, the predicted variables and the estimated error in the data.

Table4. Analysis of Nissan Urvan using Winters' Method

\begin{tabular}{|l|l|l|l|l|l|}
\hline Year & Time & Nissan Urvan (Income Generated) & Smooth & Predict & Error \\
\hline 2005 & 1 & 98073 & 99574.9 & 98513.9 & -440.88 \\
\hline 2006 & 2 & 97824 & 98099.6 & 97024.5 & 799.48 \\
\hline 2007 & 3 & 96000 & 97437.6 & 96391.7 & -391.70 \\
\hline 2008 & 4 & 95150 & 96189.6 & 95129.4 & 20.58 \\
\hline 2009 & 5 & 90200 & 95194.0 & 94134.0 & -3933.96 \\
\hline 2010 & 6 & 88500 & 93291.1 & 92074.5 & -3574.50 \\
\hline 2011 & 7 & 86100 & 90798.1 & 89446.8 & -3346.81 \\
\hline 2012 & 8 & 84897 & 88767.3 & 87282.3 & -2385.32 \\
\hline 2013 & 9 & 83400 & 86291.5 & 84720.5 & -1320.52 \\
\hline 2014 & 10 & 83000 & 84585.7 & 82959.3 & 40.66 \\
\hline
\end{tabular}

Table 5 shows the forecasting results of the data using winters' method of analysis. The forecast shows future five years income generated in the aforementioned company using their Nissan Urvan product.

Table5. Forecasting Results of Winters' Method

\begin{tabular}{|l|l|l|l|l|}
\hline Year & Time Code & Forecast & Lower & Upper \\
\hline 2015 & 11 & 81015.3 & 77033.0 & 84997.5 \\
\hline 2016 & 12 & 79724.3 & 75679.7 & 83769.0 \\
\hline 2017 & 13 & 77779.0 & 73664.8 & 81893.2 \\
\hline 2018 & 14 & 76474.7 & 72284.1 & 80665.2 \\
\hline 2019 & 15 & 74542.6 & 70269.2 & 78816.1 \\
\hline
\end{tabular}

Figure 3 reveals the results of winters' method analysis. It shows the trend of the data, fitness of the data, actual data plot, forecasting results of the data, smoothing constants, 95\% probability confidence level in the forecasting limits and the accuracy measures in the data.

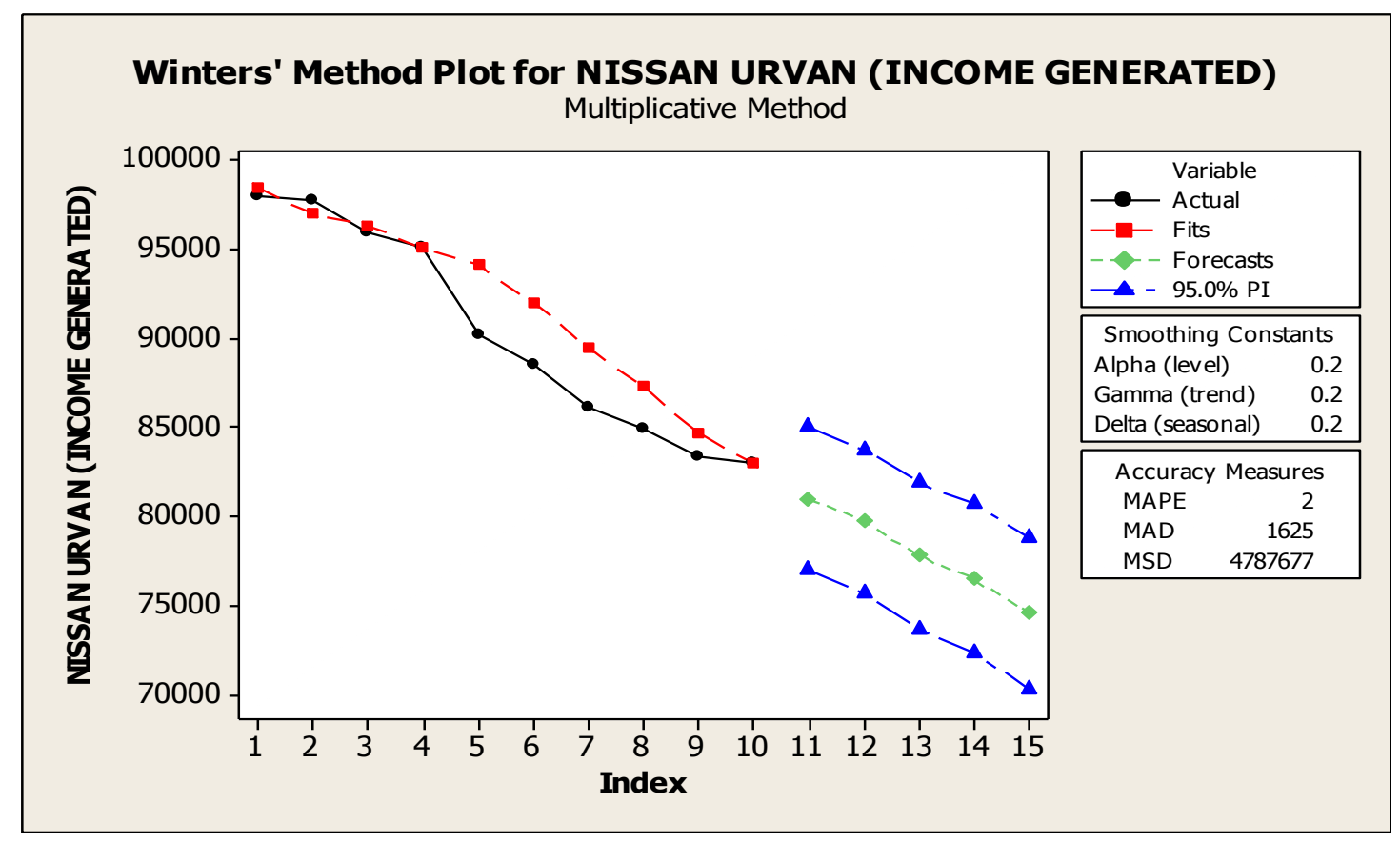

Figure3. Winters' Method Plot for Nissan Urvan (Income Generated)

\section{ARIMA Model: NisSan URVAN (INCOME GENERATED)}

Table 6 shows the iterations of the ARIMA techniques. The result shows that the iteration table could not converge after 25 iterations. 
Godwin, Harold C. et al.

Table6. Estimates at each iteration

\begin{tabular}{|c|c|c|c|c|c|c|c|}
\hline Iteration & SSE & & & Para & neters & & \\
\hline & & Parameter 1 & Parameter 2 & Parameter 3 & Parameter 4 & Parameter 5 & Parameter 6 \\
\hline 0 & 382569526 & 0.100 & 0.100 & 0.100 & 0.100 & 0.100 & 0.100 \\
\hline & 90314.500 & & & & & & \\
\hline 1 & 258682003 & -0.050 & 0.179 & 0.149 & 0.018 & 0.195 & 0.238 \\
\hline & 90778.850 & & & & & & \\
\hline 2 & 185961866 & -0.200 & 0.217 & 0.229 & -0.078 & 0.262 & 0.344 \\
\hline & 90935.808 & & & & & & \\
\hline 3 & 139351884 & -0.350 & 0.263 & 0.329 & -0.220 & 0.313 & 0.431 \\
\hline & 90984.678 & & & & & & \\
\hline 4 & 106347022 & -0.500 & 0.280 & 0.448 & -0.366 & 0.378 & 0.507 \\
\hline & 91018.970 & & & & & & \\
\hline 5 & 84963141 & -0.650 & 0.237 & 0.557 & -0.484 & 0.482 & 0.581 \\
\hline & 91026.339 & & & & & & \\
\hline 6 & 75961601 & -0.800 & 0.109 & 0.586 & -0.522 & 0.586 & 0.638 \\
\hline & 90906.676 & & & & & & \\
\hline 7 & 71234165 & -0.823 & -0.041 & 0.501 & -0.463 & 0.573 & 0.618 \\
\hline & 90835.462 & & & & & & \\
\hline 8 & 65651784 & -0.896 & -0.191 & 0.404 & -0.421 & 0.543 & 0.579 \\
\hline & 90842.324 & & & & & & \\
\hline 9 & 60579037 & -0.971 & -0.341 & 0.299 & -0.385 & 0.507 & 0.540 \\
\hline & 90936.386 & & & & & & \\
\hline 10 & 56329059 & -1.056 & -0.491 & 0.188 & -0.361 & 0.461 & 0.506 \\
\hline & 91130.684 & & & & & & \\
\hline 11 & 52692540 & -1.150 & -0.641 & 0.072 & -0.370 & 0.399 & 0.487 \\
\hline & 91504.350 & & & & & & \\
\hline 12 & 50684254 & -1.210 & -0.719 & 0.009 & -0.410 & 0.349 & 0.483 \\
\hline & 91913.245 & & & & & & \\
\hline 13 & 49312697 & -1.272 & -0.803 & -0.051 & -0.435 & 0.302 & 0.460 \\
\hline & 92289.411 & & & & & & \\
\hline 14 & 48015439 & -1.310 & -0.859 & -0.097 & -0.480 & 0.252 & 0.448 \\
\hline & 92676.104 & & & & & & \\
\hline 15 & 46300966 & -1.379 & -0.953 & -0.164 & -0.514 & 0.183 & 0.407 \\
\hline & 93134.893 & & & & & & \\
\hline 16 & 43014368 & -1.418 & -1.012 & -0.231 & -0.606 & 0.061 & 0.357 \\
\hline & 93728.318 & & & & & & \\
\hline 17 & 38615776 & -1.464 & -1.075 & -0.301 & -0.674 & -0.089 & 0.269 \\
\hline & 94275.460 & & & & & & \\
\hline 18 & 34421721 & -1.470 & -1.079 & -0.340 & -0.745 & -0.239 & 0.188 \\
\hline & 94675.585 & & & & & & \\
\hline 19 & 30525942 & -1.473 & -1.078 & -0.374 & -0.809 & \begin{tabular}{|l|}
-0.389 \\
\end{tabular} & 0.105 \\
\hline & 95046.850 & & & & & & \\
\hline 20 & 27063381 & -1.481 & -1.085 & -0.408 & -0.866 & -0.539 & 0.021 \\
\hline & 95430.560 & & & & & & \\
\hline 21 & 24065685 & -1.497 & -1.115 & -0.451 & -0.921 & -0.689 & -0.063 \\
\hline & 95853.605 & & & & & & \\
\hline 22 & 21556091 & -1.520 & -1.176 & -0.511 & -0.969 & -0.839 & -0.148 \\
\hline & 96304.428 & & & & & & \\
\hline 23 & 19692591 & -1.533 & -1.266 & -0.603 & -0.992 & -0.989 & -0.237 \\
\hline & 96687.472 & & & & & & \\
\hline 24 & 18368366 & -1.505 & -1.382 & -0.753 & -0.927 & -1.128 & -0.331 \\
\hline & 96831.829 & & & & & & \\
\hline 25 & 17792468 & -1.534 & -1.521 & -0.850 & -0.896 & -1.197 & -0.328 \\
\hline & 96776.194 & & & & & & \\
\hline
\end{tabular}

Table 7 shows the coefficient of the model used to forecast the future result. The method develops six parameters to estimate the coefficient. The table also reveals the significance level of the six estimated parameters for the analysis of the results in ARIMA technique. 
Application of Forecasting Techniques in Nissan Urvan Income Generation of Anambra State Transport Sector

Table7. Final Estimates of Parameters

\begin{tabular}{|l|l|l|l|l|}
\hline Type & Coef & SE Coef & T & P \\
\hline MA 1 & -1.5340 & 0.5508 & -2.79 & 0.069 \\
\hline MA 2 & -1.5211 & 0.9992 & -1.52 & 0.225 \\
\hline MA 3 & -0.8497 & 0.7602 & -1.12 & 0.345 \\
\hline SMA 2 & -0.8963 & 0.9365 & -0.96 & 0.409 \\
\hline SMA 4 & -1.1975 & 0.7628 & -1.57 & 0.214 \\
\hline SMA 6 & -0.3278 & 1.2199 & -0.27 & 0.806 \\
\hline Constant & 96776 & 1938 & 49.94 & 0.000 \\
\hline Mean & 96776 & 1938 & & \\
\hline
\end{tabular}

Where; MA = Mean Average, $\mathrm{MA}=$ Square Mean Average, $\mathrm{SE}=$ Square error, $\mathrm{T}=\mathrm{Critical}$ Point, $\mathrm{P}=$ Parameters.

Table 8 shows the forecasting results of the data using ARIMA method of analysis. The forecast shows future five years income generated in the aforementioned company using their Nissan Urvan product.

Table8. Forecasts from period 10

\begin{tabular}{|l|l|l|l|l|}
\hline Year & Time Code & Forecast & Lower & Upper \\
\cline { 4 - 5 } & & & \multicolumn{2}{|c|}{ 95\% Limits } \\
\hline 2015 & 11 & 86053 & 81488 & 90618 \\
\hline 2016 & 12 & 89557 & 81198 & 97916 \\
\hline 2017 & 13 & 92127 & 78283 & 105971 \\
\hline 2018 & 14 & 93646 & 76477 & 110816 \\
\hline 2019 & 15 & 94793 & 74022 & 115564 \\
\hline
\end{tabular}

Figure 4 reveals the results of ARIMA method of analysis. It shows the actual data plot and forecasting results of the data.

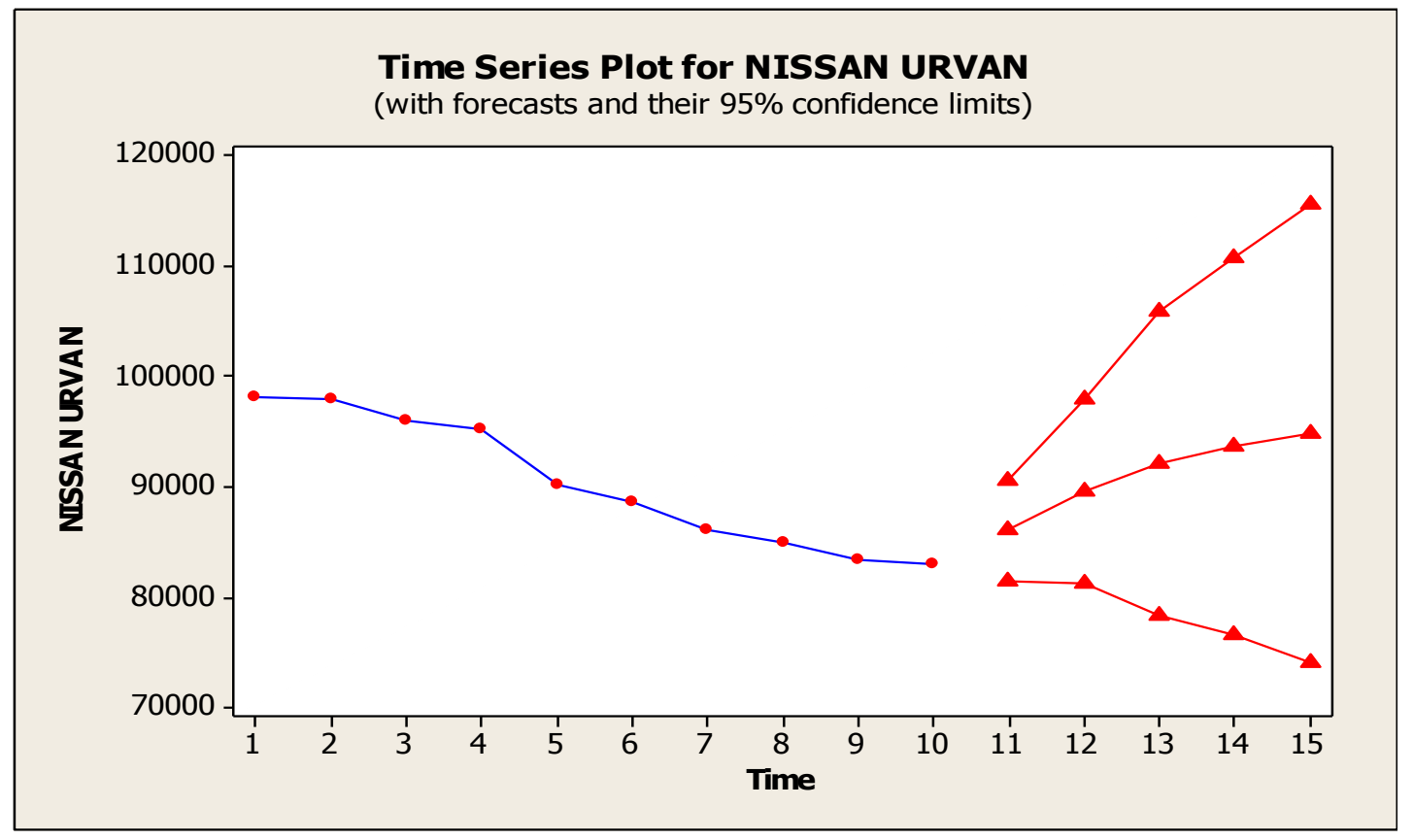

Figure4. Time Series Plot for Nissan Urvan

Table 9 is the combination of the winters' forecasting results, ARIMA forecasting results and Decomposition forecasting results for future five years of the case company.

Table9. Forecasting Results of the Income Generated in Nissan Urvan

\begin{tabular}{|l|l|l|l|}
\hline Years & Forecasting Results & \multicolumn{3}{|l|}{} \\
\hline & Winter Method & Decomposition Method & ARIMA Method \\
\hline 2015 & 81015.3 & 79267.4 & 86053 \\
\hline 2016 & 79724.3 & 77805.8 & 89557 \\
\hline 2017 & 77779.0 & 75354.2 & 92127 \\
\hline 2018 & 76474.7 & 73867.7 & 93646 \\
\hline 2019 & 74542.6 & 71441.1 & 94793 \\
\hline
\end{tabular}




\section{DISCUSSION}

The discussions of the results were based on the data, analysis of the data, charts developed, tables and the results of the data. Table 1 shows the yearly data for income generated from the Nissan Urvan in Anambra State Transport Sector which form the major data used for the analysis and the forecast while Table 9 displays the forecasting results of the income generated in Nissan Urvan from the three models used. The data were analyzed on yearly basis to observe it's seasonal and trend influence on the data as demonstrated in figures $(1,2,3,4)$. The analysis also reveals that the results were within $95 \%$ confidence limit as shown in figure 4 . It was also observed that there are residuals in the data, the upper and lower boundaries in each of the forecast techniques (i.e. time series decomposition method of analysis, winter's method and ARIMA method of forecasting) selected to run this analysis. From the forecasting results it is more advisable and recommendable to make use of the time series decomposition method in this research than the winter method and ARIMA method because; it is more accurate with less error than the other two methods and secondly, time series decomposition method incorporate both trend and seasonality in its model. However, time series decomposition forecasting results were recommended.

\section{Conclusion}

The development of an optimum maintenance and replacement strategies in transportation industries that integrates adequately all the key maintenance requirements is critical to the attainment of high performance by supporting improved transportation functions. In general, three forecasting techniques have been looked into from the view point of how best to separate trends and growth cycles, that is, fluctuations in data adjusted for long term and seasonal movements. The most difficult problem for these forecasting models employed in this research work arises out of the residuals in the data, the upper and lower boundaries in each of the forecast techniques. However, it is therefore recommended that further improvement can be made on the software programme such that it reads data from a specified data resource. This will help transport operators to improve on income generation. Having observed the forecasting results, it is also recommended that the case company should be more mindful of their vehicles maintainability and repairs for it might be the cause of continuous dropping in generated income revenue of the Nissan Urvan vehicles. More so, it is recommended that the replacement of the vehicles when the need arises should be seen as critical.

\section{REFERENCES}

[1] Davenport, N.S., Anderson, M.D. and Farrington, F.A.,(2005).Development and Application of a Vehicle Procurement Model for Rural Fleet Asset Management. Transportation Research Record, No. 1927, pp. 123-127.

[2] Dwaikat, N.(2009).Forecasting in Production Planning \& Inventory Control; Industrial Engineering Department, An-Najah National University..

[3] Fischer, M. (2010). Modeling and Forecasting Energy Demand: Principles And Difficulties; Troccoli (ed.), Management of Weather and Climate Risk in the Energy Industry, () Springer Science Business Media B.V. 2010

[4] Godwin,H.C. and Okafor, C.E.(2013).Modified Trend and Seasonal Time Series Analysis for Operation: A Case of Soft Drink Production. International Journal of Engineering Research in Africa, pp63-72.

[5] Latham, A.(2008).Differences in Forecasting Demand for a Product Versus a Service; Demand Media.

[6] Lin, J. K, Eamonn, L, \& Chiu, B. (2003). "A symbolic representation of time series, with implications for streaming algorithms". Proceedings of the 8th ACM SIGMOD Workshop on Research issues in data mining and knowledge discovery. New York: ACM Press. Doi: $10.1145 / 882082.882086$

[7] Nahmias, S. (2009). Production and Operations Analysis.

[8] Nakagawa, T. and Osaki, S., (1974). The Optimum Repair Limit Replacement Policies. Operational Research Quarterly, Vol. 25, No.2, pp. 311-317.

[9] Scott, A., Fred, A. G., and Kesten, C. G.(2013). "Answers to Frequently Asked Questions". Retrieved May 15, 2013.

[10] Shumway, R. H. (1988). Applied statistical time series analysis. Englewood Cliffs, NJ: Prentice Hall. ISBN 0130415006.

[11] Steven, S. (2007). Applications of Dynamic Programming. State University of New York Stony Brook, NY 11794-4400.pp 13-20. 